\title{
Study of $\mathrm{Li}^{+}$lon-exchanger $\mathrm{Mg}_{2} \mathrm{TiO}_{4}$ Jin-He JIANG ${ }^{a^{*}}$, Su-Qing WANG ${ }^{b}$ and Sheng-Bin ZHANG ${ }^{c}$
}

Department of Chemistry and Chemical Engineering ,Weifang University, Weifang, 261061,China

a jiangjinhe2020@163.com, ${ }^{b}$ wsuqing66@163.com, ${ }^{\mathrm{C}} \mathrm{zsb1810@163.com}$

${ }^{*}$ Corresponding author Jin-He JIANG

Keywords: Spinel-type metal oxides ion-exchange mechanism Solid state reaction $\mathrm{Mg}_{2} \mathrm{TiO}_{4}$

\begin{abstract}
Spinel-type metal oxides, magnesium-titanium oxide $\left(\mathrm{Mg}_{2} \mathrm{TiO}_{4}\right)$, was prepared by a solid state reaction crystallization method. The spinel construction of $\mathrm{Mg}_{2} \mathrm{TiO}_{4}$ was conformed by XRD. The results showed that the $\mathrm{Li}^{+}$extraction/insertion be progressed mainly by an ion-exchange mechanism. The acid treated samples had an ion exchange capacity of $13.9 \mathrm{mmol} / \mathrm{g}$ for $\mathrm{Li}^{+}$.
\end{abstract}

\section{Introduction}

The inorganic ion-exchange preparation has the advantage of thermo-stability and radiation resistance, synthesis simple and good selectivity etc. In addition, it appears the fine speciality in dealing with nuclear waste, gathering and separating of metal ions and chromatogram analysis[1-2].In this paper, inorganic ion exchanger $\left(\mathrm{Mg}_{2} \mathrm{TiO}_{4}\right)$ with a spinel structure ion memory was synthesized by a solid state reaction crystallization method., which is different the reported in the literatures[3-5], and its ion-exchange properties were studied.

\section{Experimental Section}

Reagent and Instruments. $\mathrm{MgO}$ and $\mathrm{TiO}_{2}$ were all analytical reagents; pure ethanol; $\mathrm{D} / \mathrm{max}-\mathrm{A}$ type X-ray diffraction instrument; Dx-170 type ion chromatogram instrument; XQM planetary ball mill; AA-670 atom absorption spectrum instrument; tubular-furnace.

Synthesis and Identifiable of $\mathbf{M g}_{2} \mathbf{T i O}_{4}$. The pure ethanol was dropped into a XQM planetary ball mill mixed powder of $\mathrm{MgO}$ and $\mathrm{TiO}_{2}$ with a $\mathrm{Mg} / \mathrm{Ti}$ mole ration of 2:1 at the condition of constant rate churning. After 8 hours, the mixture was mixed completely. After mixing fully, the mixture was pressed to tablet by tablet press machine. Then the tablet was heat-treated for $4.5 \mathrm{~h}$ at $900^{\circ} \mathrm{C}$ to obtain the Mg-Ti metal compound, the sample was designed as MgTi-900, whose theoretical formula was $\mathrm{Mg}_{2} \mathrm{TiO}_{4}$. Then it was analysed of x-ray diffraction and compared to literature[3-4].

Composition analysis: A $0.2 \mathrm{~g}$ portion of sample was dissolved with acid. The $\mathrm{Mg}$ and $\mathrm{Ti}$ contents were determined by atomic absorption spectrometry.

The Cation Extraction of Mg-Ti metal compound and Acid Modification. Four $0.200 \mathrm{~g}$ portions of sample (MgTi-900 compound) were immersed in a $\mathrm{HNO}_{3}$ solution $(50 \mathrm{ml})$ of $0.01 \mathrm{M}$, $0.1 \mathrm{M}, 1 \mathrm{M}$ and $10 \mathrm{M}$ respectively with shaking in constant temperature water at $25^{\circ} \mathrm{C}$. After 3 days, take the supernatant solution to determine the cation concentration, test its acid proof ability and the extraction ration of $\mathrm{Ti}^{4+}$.

A $5 g$ portion of sample (MgTi-900) was immersed in a $1 \mathrm{M} H N O_{3}$ solution $(500 \mathrm{~mL})$ with intermittent shaking in constant temperature water at $25^{\circ} \mathrm{C}$. After 7 days, remove the supernatant solution and add new $\mathrm{HNO}_{3}$ solution. Repeating that for twice, then the initial sample was transformed to H-type sample, washed with water and air-dried. The sample obtained by thermal crystallized at $900^{\circ} \mathrm{C}$ and acid modified was designated as MgTi-900 (H).

Saturation Capacity of Exchange. Weigh five 0.5g portions of MgTi-900 (H), then each portion was immersed in a $0.1 \mathrm{M}$ solution $(10 \mathrm{~mL})$, containing $\mathrm{Li}^{+}, \mathrm{Na}^{+}, \mathrm{K}^{+}, \mathrm{Rb}^{+}$and $\mathrm{Cs}^{+}$respectively, diluted to $100 \mathrm{~mL}$, shaken in constant temperature water at $25^{\circ} \mathrm{C}$. After saturation exchanging (namely, after 10 days by literature[3-4]) the solutions were filtered by subminiature aperture sieve, and the cation concentration was determined. At the same time, do vacant experiment. Last, the 
inorganic exchanger saturation capacity of exchange for alkali-metal-ions obtained by decrease quantity.

Distribution Coefficient (Kd). After weighing four $0.100 \mathrm{~g}$ portions of MgTi-900 (H), each portion of sample was immersed in a $0.05 \mathrm{M}$ mixed solution $(0.200 \mathrm{~mL})$ containing $\mathrm{Li}^{+}, \mathrm{Na}^{+}, \mathrm{K}^{+}, \mathrm{Rb}^{+}$ and $\mathrm{Cs}^{+}\left(\mathrm{Cl}^{-} / \mathrm{OH}^{-}\right.$rations are different in each solution, $\mathrm{C}\left(\mathrm{Cl}^{-}\right)+\mathrm{C}\left(\mathrm{OH}^{-}\right)=0.1 \mathrm{M}, \mathrm{C}=\mathrm{Li}^{+}, \mathrm{Na}^{+}, \mathrm{K}^{+}, \mathrm{Rb}^{+}$ and $\left.\mathrm{Cs}^{+}\right)$. The alkali-metals ions total concentration all was $1.0 \times 10^{-3} \mathrm{M}$ by adding $9 \mathrm{~mL}$ distilled water. After the samples were shaken for 7 days in constant temperature water at $25^{\circ} \mathrm{C}$ and were filtered, cation concentrations in each samples were obtained.

\section{Results and Discussion}

Compound and Appraisement of $\mathbf{M g}_{2} \mathbf{T i O}$. The X-ray diffraction pattern of compound metal oxide $\left(\mathrm{Mg}_{2} \mathrm{TiO}_{4}\right)$, crystallized was shown in figure 1 . The structure of compound metal oxide $\mathrm{Mg}_{2} \mathrm{TiO}_{4}$ crystallized at $900^{\circ} \mathrm{C}$ was much perfect.

We know from chemical analysis, the composition of MgTi-900 is $\mathrm{Mg}_{1.97} \mathrm{Ti}_{0.99} \mathrm{O}_{3.96}$, whose chemical component is basically corresponded with the composition of spinel-type metal oxides.

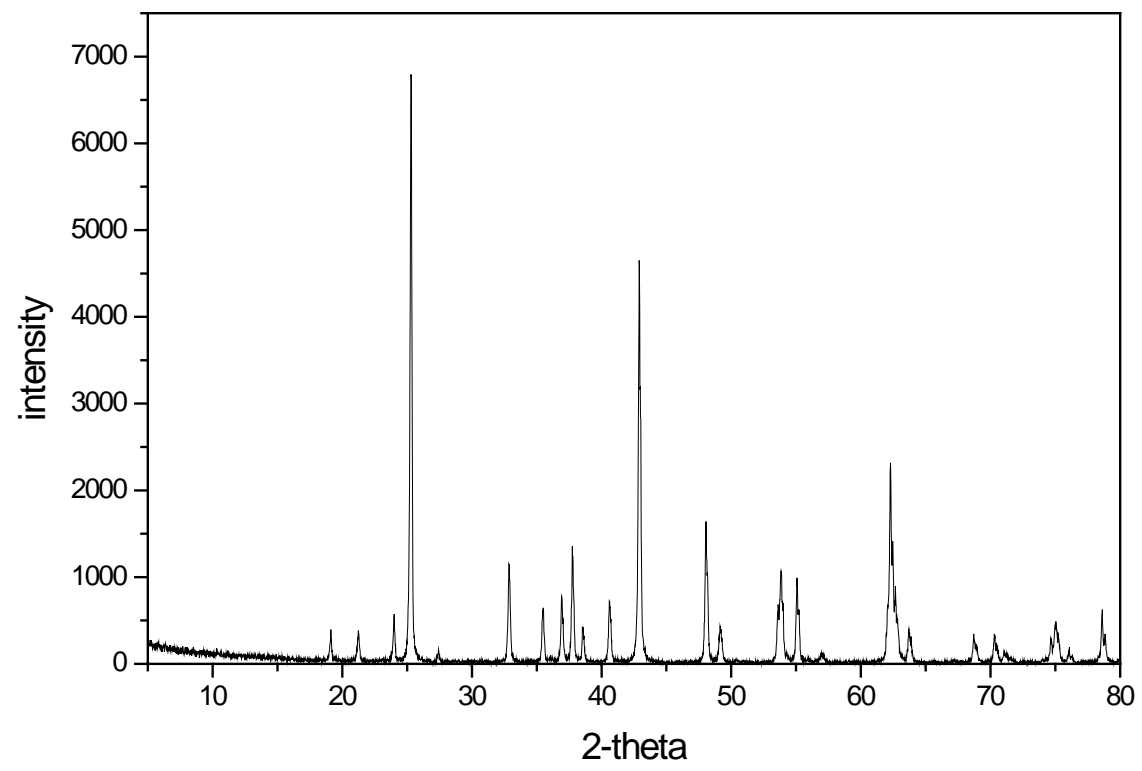

Fig.1 The powder's X-ray figures of $\mathrm{Mg}_{1.97} \mathrm{Ti}_{0.99} \mathrm{O}_{3.96}$ crystal

Cation Extraction of Metal Compound Mg-Ti and Acid Modification. The extraction ration of $\mathrm{Mg}^{2+}$ and $\mathrm{Ti}^{4+}$ from MgTi-900 in different concentration $\mathrm{HNO}_{3}$ solution is shown in Figure2. we know from Figure2, the extractabilities of $\mathrm{Mg}^{2+}$ are $35 \% \sim 78 \%$ and $\mathrm{Ti}^{4+}$ are $2.4 \% \sim 8.0 \%$. Those indicate that the extractabilities of $\mathrm{Mg}^{2+}$ are higher than those of $\mathrm{Ti}^{4+}$ when exchanger was immersed in $1 \mathrm{M}$ acid solution, correspounding with the exchanger condition was better.(1 $\mathrm{N}$, $\left.\mathrm{Mg}^{2+} 73 \%, \mathrm{Ti}^{4+} 6.1 \%\right)$

X-ray diffraction of MgTi-900 (H), which is the acid modification product, is shown in Figure1. As shown, the structure of $\mathrm{MgTi}-900(\mathrm{H})$ is nearly constant, which is spinel oxide type too. It indicate that the exchanger is steady. The analysis indicate the composition of MgTi-900 $(\mathrm{H})$ was $\mathrm{H}_{2.87} \mathrm{Mg}_{1.53} \mathrm{Ti}_{0.93} \mathrm{O}_{3.64}$, whose component of $73 \% \mathrm{Mg}^{2+}$ transformed to $\mathrm{H}^{+}$compared with the composition $\mathrm{Mg}_{1.97} \mathrm{Ti}_{0.99} \mathrm{O}_{3.96}$ before acid-treated. Then the specific $\mathrm{Mg}^{2+}$ of exchanger were extracted fulfill basically and remained the H-type identified with initial type. 


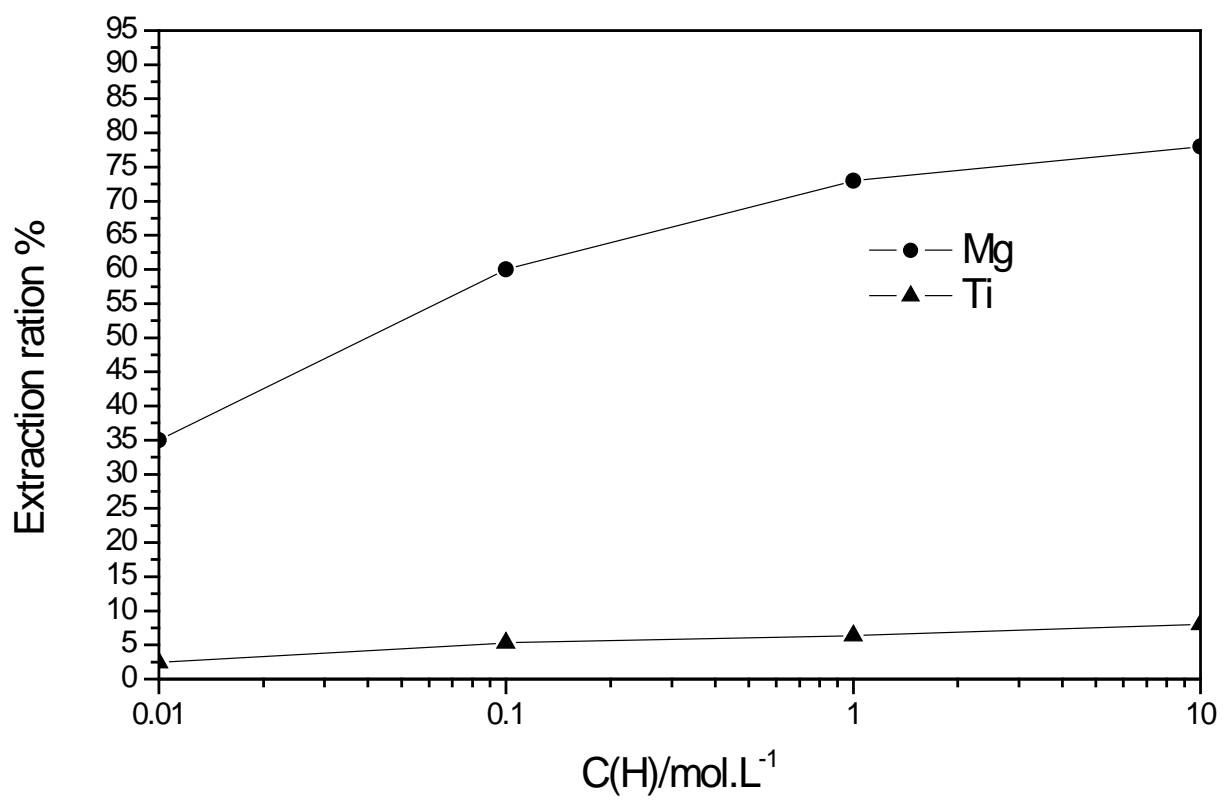

Fig.2 Extraction ration of cations from MgTi-900 in nitric acid solution

Saturation Capacity of Exchange. The relation between radius and saturated ion exchange capacity of MgTi-900 (H) for alkali was shown in figure 3. Known from figure 3, the capacity of exchange for $\mathrm{Li}^{+}$was much higher than those for other alkali ions. The capacity for $\mathrm{Li}^{+}$is $13.9 \mathrm{mmol} \cdot \mathrm{g}^{-1}$. It proved that the ion exchange synthesized has higher capacity of exchange, and better remembering of exchange for $\mathrm{Li}^{+}$. The effect factors of saturation capacity of exchange of MgTi-900 (H) are: 1) The $\mathrm{Li}^{+}$in exchange solution must be removed previously, because $\mathrm{Li}^{+}$ exchanged with exchanger vacancy site when existing too much $\mathrm{Li}^{+}$; 2) The experimental results shown that the exchange capacity of ion exchanger for $\mathrm{Li}^{+}$is much higher than those for other alkali ions in thin solution, which indicate that the ion-exchange reaction is carried out between and bare ions; 3) At the time of exchange, a $\mathrm{Li}^{+}$was replaced by one $\mathrm{H}^{+} \cdot \mathrm{Li}^{+}$not only entered the vacancy site but also exchanged with the $\mathrm{H}^{+}$of surface. Therefore, MgMnTi-900 (H) has a higher exchange capacity for $\mathrm{Li}^{+}$.

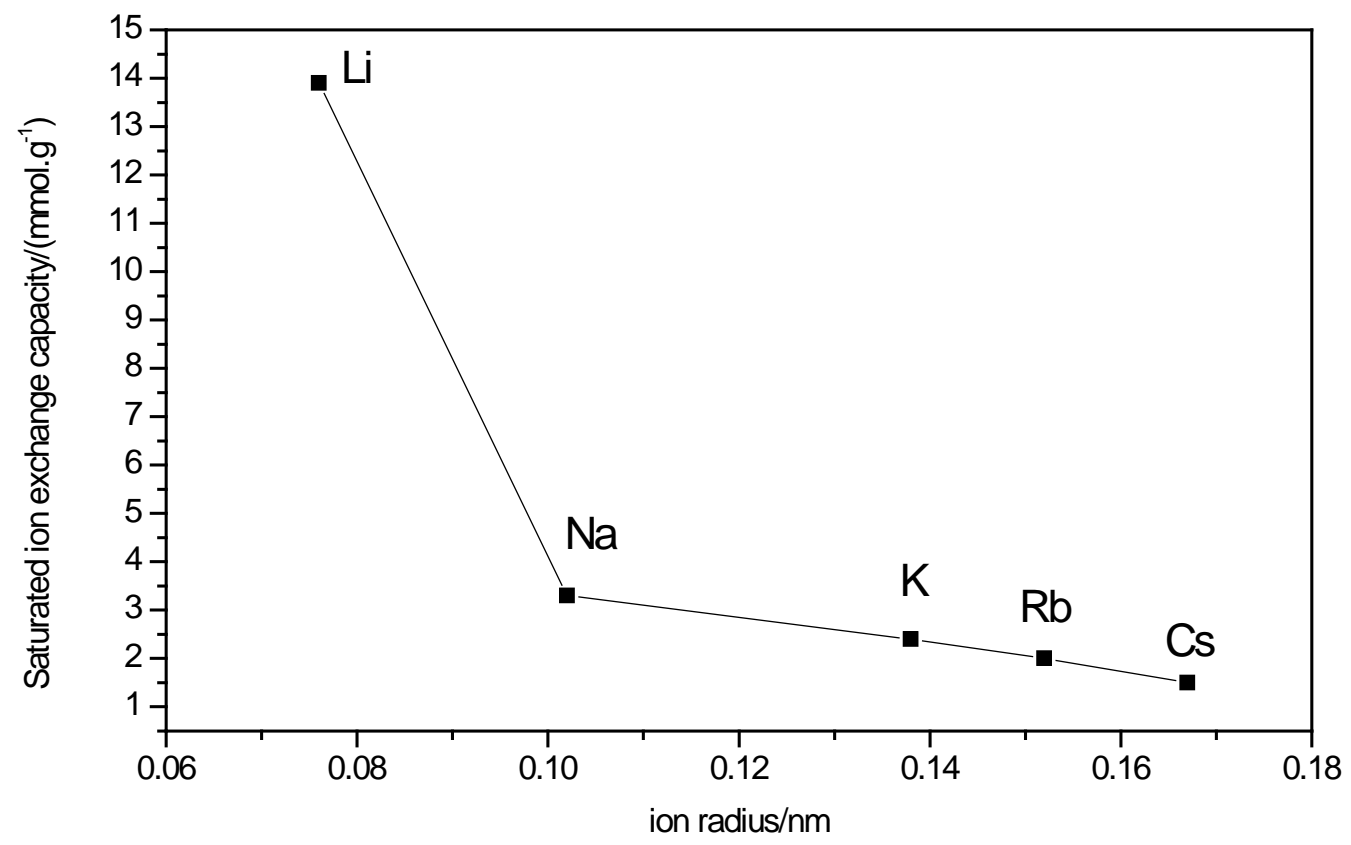

Fig.3 Relation between ion radius and saturated ion exchange capacity of MgTi-900 for alkali ions 
Distribution coefficient(Kd). Kd values can be the token of exchange selectivity of MgTi-900 (H) for correlate ions. Shown in figure 4, Kd values of MgTi-900 (H) for alkali ions are larger and larger with an increase $\mathrm{pH}$ over the $\mathrm{pH}$ region studied. The selectivity sequence of MgTi-900 for alkali metal ions as follows:

$$
\mathrm{Li}^{+}>\mathrm{Cs}^{+}>\mathrm{Rb}^{+}>\mathrm{K}^{+}>\mathrm{Na}^{+}
$$

It indicates that MgTi-900 (H) has a better ion selectivity for $\mathrm{Li}^{+}$. Ion-exchange reaction is reversible reaction. The reaction of $\mathrm{H}^{+}$in ion-exchanger with alkali metal ions in solution as follows(example for $\mathrm{Li}^{+}$):

$$
E-2 H+2 L i^{+} \Leftrightarrow E-2 L i+2 H^{+}
$$

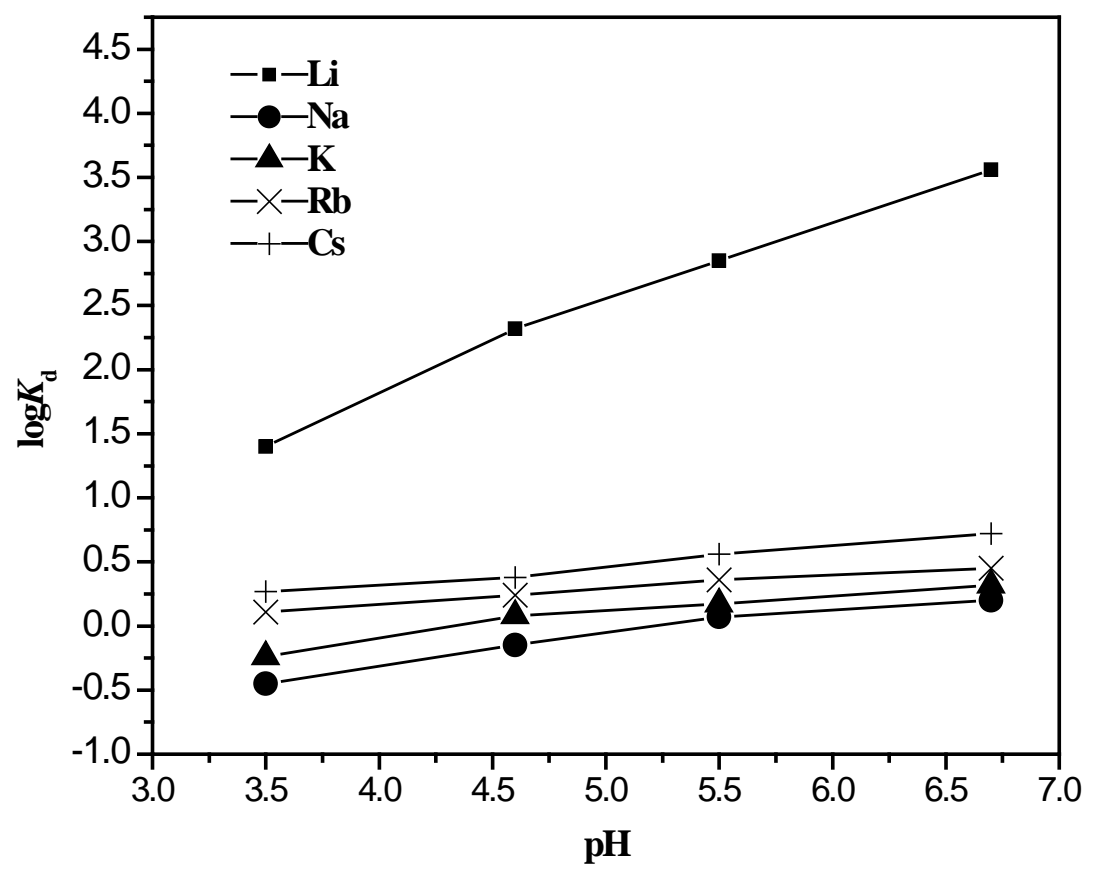

Fig.4 Distribution coefficient of MgTi-900(H)for alkali ions

\section{Conclusions}

The $\mathrm{Mg}_{2} \mathrm{TiO}_{4}$ of spinel-type metal oxide show a capacity extraction/insertion of $\mathrm{Li}^{+}$in the aqueous phase, by X-ray, saturation capacity of exchange and Kd measurement, etc. It has high selectivity to $\mathrm{Li}^{+}$. The $\mathrm{Li}^{+}$-extracted samples show a high selectivity and a large capacity for $\mathrm{Li}^{+}$among alkali metal ions.

\section{Acknowledgments}

This research was supported by the Chinese National Nature Science Foundation (51541205), The national Spark Program (2014GA740047) and Nature Science Foundation of Shandong Province(ZR2013BL016).

\section{References}

[1] D.Q.Dong, J.Zhong, D.L.Liu, Y.F.Liu: $\mathrm{LiCu}_{0.5} \mathrm{Mn}_{1.5} \mathrm{O}_{4}$ synthesis and $\mathrm{Li}^{+}$extraction/reaction with it in the aqueous phase[J]. China Journal of Applied Chemistry . 1998,15(3),11-16 
[2] Peng Z. S.Synthesis and electrochemical studies on spinel phase LiMn2O4 cathode material prepared by different proceses[J]. Rare Metal, 1999,18(2),143-148

[3] Zhong h.. Prpperty of H2TiO3 type ion-exchangers and extraction of lithium from brine of natural gas wells [J]. Chinese Journal of Applied Chemistry.2000,17(3),307-312

[4] Jiang J.H.,Dong D.Q.,Li J.L. Synthesis of Li4Mn0.5Ti0.5O4 and its selectivity to Li+ exchange[J]. Chinese Journal of Applied Chemistry.2006,23(4),357-362

[5] Dan Li, Tian Long Deng, Bai Sun. Inorganic ion exchange extraction of lithium from brine research[J]. Guangdong Trace Elements Science, 2007, 14 (1): 6-10. 